\title{
Sutilezas e tessituras do ambiente hospitalar: o cotidiano de uma enfermaria pediátrica de média e alta complexidade ${ }^{1}$
}

\author{
Mariana Pereira Simonato, Rosa Maria de Araujo Mitre \\ Departamento de Ensino, Instituto Nacional de Saúde da Mulher, da Criança e do Adolescente Fernandes \\ Figueira, Fundação Oswaldo Cruz - FIOCRUZ, Rio de Janeiro, RJ, Brasil.
}

\begin{abstract}
Resumo: Objetivo: Este artigo procurou investigar o cotidiano de crianças e de adolescentes internados em uma enfermaria de alta e média complexidade. Método: Tratou-se de uma pesquisa exploratória cujo procedimento técnico foi o estudo de campo. Dentro da abordagem qualitativa, optou-se por escolher a perspectiva etnográfica, com a observação participante e os registros em diários de campo. O material da coleta de dados de campo foi lido exaustivamente a fim de relacioná-lo ao referencial teórico, utilizando a análise de conteúdo na modalidade temática. Resultados: Ao estudar o cotidiano de uma enfermaria pediátrica de média e alta complexidade, foi possível constatar: que ele é permeado por intervenções da equipe de saúde; que as crianças e os adolescentes têm pouco espaço para exercer a autonomia nos cuidados em saúde; que os espaços para outras atividades são escassos; e que os objetos hospitalares estão presentes na quase totalidade das cadeias operatórias, extrapolando aquelas ligadas aos cuidados em saúde. Conclusão: Acredita-se que também é um papel da equipe de saúde problematizar a vida cotidiana hospitalar e, por meio de tecnologias relacionais, criar, facilitar e valorizar os espaços de liberdade possíveis e o exercício da autonomia para que as crianças e os adolescentes hospitalizados conduzam a vida cotidiana hospitalar com maior autonomia.
\end{abstract}

Palavras-chave: Criança, Adolescente, Hospital.

\section{Hospital subtleties and tessitura: daily routine of a pediatric ward of medium and high complexity}

\begin{abstract}
Objective: This study aimed at investigating the daily lives of children and adolescents hospitalized in a nursing ward of high and medium complexity. Method: This was an exploratory research whose technical procedure consisted in a field study. In the qualitative approach, we decided to choose the ethnographic perspective. The material collected was thoroughly read and related to the theoretical framework by means of content analysis in the thematic modality. Results: The study of the daily routine of the medium and high complexity pediatric ward showed that this characterized by a high number of interventions carried out by the health team; the hospitalized children and adolescents have little room to exercise their autonomy in health care; there is little space for other activities; and the hospital equipment is present in almost all the operational chains, extrapolating those related to health care. Conclusion: Therefore, the health care must discuss the hospital daily routine and create, facilitate and enhance, through relational technologies, the room for freedom and autonomy so that hospitalized children and adolescents may experience their life at the hospital more autonomously.
\end{abstract}

Keywords: Child, Adolescent, Hospital.

Autor para correspondência: Mariana Pereira Simonato, Serviço de Oncologia Pediátrica, Praça Cruz Vermelha, 23, Centro, CEP 20230-130, Rio de Janeiro, RJ, Brasil, e-mail: marianasimonato@hotmail.com

Recebido em Maio 21, 2016; 1ª Revisão em Nov. 30, 2016; Aceito em Fev. 1, 2017. 


\section{Introdução}

A hospitalização na infância ocorre em contexto de crise aguda ou quando uma patologia crônica se agrava, sendo o hospital o lugar onde se busca, de modo geral, a cura, uma melhora sintomática ou um tratamento. Porém, a dinâmica institucional do hospital poderá implicar em um leque de perdas às crianças e aos adolescentes que necessitam ficar hospitalizados e tornar esse processo de hospitalização potencialmente traumático na infância (SANTA ROZA, 1997).

As perdas, como o afastamento do ambiente familiar, dos objetos pessoais, da alimentação costumeira, do ambiente escolar, dos amigos, da rotina cotidiana, costumam acompanhar a hospitalização (SANTA ROZA, 1997; MITRE; GOMES, 2004) e provocam uma ruptura no cotidiano e a necessidade da construção de um novo modo de agir no cotidiano hospitalar, com todas as particularidades que esse ambiente exige.

Assim, se o cotidiano se transforma, as açóes que o tornam particular também serão transformadas. Segundo Heller (2008), a vida cotidiana é a do homem inteiro, na qual se colocam seus sentidos, todas as suas capacidades intelectuais, suas habilidades manipulativas, seus sentimentos, paixóes, ideias, ideologias.

Pode-se dizer que a hospitalização modifica o jeito de agir no mundo, seja por implicar em diversas perdas ou por requerer novas açóes específicas. Neste processo, crianças e adolescentes têm suas cadeias operatórias rompidas e modificadas como consequência dessa mudança no cotidiano, sendo necessária a constituição de novas cadeias operatórias do processo de hospitalização.

As cadeias operatórias são os modos particulares de realizar as açôes no cotidiano. Leroi-Gourhan (2002) descreve as cadeias operatórias como a repetição de gestos que asseguram o equilíbrio do sujeito e seu conforto psíquico no meio social, ou seja, o jeito particular como cada pessoa realiza determinada atividade. Acredita-se que, na maioria das vezes, o processo de constituiçáo de novas cadeias operatórias náo seja simples devido à complexidade do ambiente hospitalar, ao processo de institucionalização, às relaçóes de dominação que se revelam no trabalho cotidiano (LEFEBVRE, 1991) e ao próprio sofrimento da criança e do adolescente hospitalizado.

Assim, este artigo objetivou investigar o cotidiano de crianças e de adolescentes internados em uma enfermaria de média e alta complexidade, além de descrever as cadeias operatórias presentes na hospitalização dessas crianças e adolescentes, identificar e apontar as interaçóes e práticas neste cotidiano hospitalar e refletir acerca das possibilidades e desafios sobre a potência de ação desses sujeitos no cotidiano hospitalar.

\section{Método}

Foi feita uma pesquisa exploratória com observação de campo, na qual se utilizou a perspectiva etnográfica, com a construção de um diário de campo. A escolha desse método foi feita por acreditar que ele conseguiria aproximar as pesquisadoras das sutilezas do cotidiano e das cadeias operatórias de crianças e de adolescentes em processo de hospitalização, bem como as interaçôes e as práticas existentes nele. Como afirma Laplantine (2000), a etnografia tem como centro o estudo do infinitamente pequeno e do cotidiano: os gestos, as expressóes corporais, os hábitos alimentares, a higiene, a percepção dos ruídos etc.

O estudo foi feito em uma enfermaria pediátrica de média e alta complexidade de uma instituição na região Sudeste do país de referência em saúde da criança para algumas áreas, como doenças crônicas, síndromes genéticas e malformaçóes congênitas. A escolha dessa enfermaria, que tem 14 leitos, deu-se, principalmente, pela proximidade das pesquisadoras com o campo, por ser um local de formação de profissionais e também pelo fato de as internaçôes nesse local serem, de forma geral, prolongadas. Acredita-se que, nas internaçóes prolongadas, as mudanças no cotidiano sejam mais significavas, e a constituição de novas cadeias operatórias, mais evidente. Os participantes foram todas as crianças e os adolescentes internados nessa enfermaria durante o período de coleta de dados, e náo se aplicou nenhum critério de exclusão.

Apesar de o campo ser um lugar familiar das pesquisadoras, no qual atuam ou já atuaram tanto na atividade assistencial como na pesquisa, como afirma Velho (1978) o que sempre se vê ou se encontra pode ser familiar, mas não necessariamente conhecido. Quando se propóe a investigar um campo conhecido, dispóe-se de um mapa que permite a familiarização dos cenários e das situaçóes sociais do cotidiano. Isso, no entanto, não significa que se conhecem o ponto de vista e a visão de mundo dos diferentes atores em uma situação social nem as regras que estão por detrás dessas interações.

Velho (1978) também alerta para a importância de relativizar a noçấo de objetividade quando se observa o familiar. A realidade, seja ela familiar ou exótica, sempre é filtrada por um determinado ponto de vista do observador; ela é percebida de maneira diferenciada e é sempre interpretativa. O processo 
de estranhar o familiar também se torna possível quando se é capaz de confrontar intelectualmente, e mesmo emocionalmente, diferentes versōes e interpretaçôes existentes a respeito dos fatos e das situaçóes.

A observação ocorreu durante três meses, em dias e horários diferentes, inclusive no período noturno e nos finais de semana, o que permitiu entrar em contato com os diversos cenários e acontecimentos. As observaçóes se dividiram em dois momentos: o primeiro foi observar a dinâmica geral do campo e o segundo foi fazer uma observaçáo direcionada ao que as crianças e os adolescentes internados estavam fazendo.

A análise dos dados foi conduzida pelo referencial da análise de conteúdo na modalidade análise temática, que foi operacionalizada em três etapas: pré-análise, exploração do material e tratamento dos resultados obtidos e interpretação (MINAYO, 2010). A interpretação dos dados obtidos na pesquisa de campo foi feita à luz do referencial teórico de Heller (2008), Galheigo (2003), Leroi-Gourhan (2002) e Spinoza (2013).

\section{Resultados e Discussão}

\subsection{Artesanias do cuidar}

Durante a pesquisa, estiveram internados na enfermaria 31 crianças e adolescentes, com idade entre 6 meses e 18 anos, das quais, 9 estiveram internadas durante todo o período de coleta de dados e tinham entre 9 meses e 8 anos de idade. A grande maioria estava acompanhada por suas mães ou uma figura feminina de laço. Destaca-se que esse período do desenvolvimento infantil é a fase na qual a criança é apresentada ao mundo e passa por intensas modificaçóes no seu desenvolvimento motor, cognitivo e emocional.

A maioria dos sujeitos da pesquisa possuía condiçôes crônicas e complexas de saúde ${ }^{2}$. Os diagnósticos mais frequentes foram malformação congênita, doenças genéticas e encefalopatia não progressiva da infância. A principal causa das internaçôes e da permanência por um período prolongado no hospital foram as complicaçôes pulmonares.

Outra característica dos sujeitos desta pesquisa foi a dependência de tecnologias para a manutenção da vida-nutricionais, medicamentosas ou respiratórias, entre outras. Assim, pela necessidade de estarem ligados a um ou vários aparelhos, essas crianças e adolescentes ficavam restritos ao leito ou tinham sua possibilidade de mobilidade pela enfermaria reduzida.
Durante o estudo, encontrou-se um panorama geral do cotidiano da enfermaria que se caracterizava por um despertar lento no início da manhã, com as luzes de alguns boxes apagadas e crianças e acompanhantes dormindo. A movimentação da equipe, prioritariamente de enfermagem, envolvia pouca conversa e barulho dos aparelhos. A rotina de cuidados na enfermaria começava por volta das $8 \mathrm{~h} 30$. Nesse horário, algumas crianças já estavam despertas, e a rotina do banho começava, principalmente para aquelas que estavam sem acompanhante. As crianças acompanhadas, em geral, tomavam banho mais tarde.

O banho foi, talvez, a atividade que mais demandava tempo no cotidiano da hospitalização. Ele era realizado, na grande maioria das vezes, no leito, e, de forma geral, apenas aqueles que podiam ficar sem o aporte de oxigênio por um período e não possuíam acesso venoso podiam tomar banho no banheiro. Quando a criança ou o adolescente estava desacompanhado, ele era realizado por um profissional da equipe de enfermagem, geralmente um técnico. Em geral, esse encontro era silencioso, talvez porque no banho fossem necessários cuidados complexos com os acessos, curativos e estomias, além da utilização de bacias de alumínio. Quando esse cuidado de higiene era realizado pela mãe, os objetos usados eram diferentes, principalmente o uso de bacias ou banheiras de plástico, em vez das de alumínio. Esse momento parecia ser mais prazeroso para a criança e o adolescente ao possibilitar brincadeiras e maior envolvimento.

Logo após o banho, eram realizados os cuidados com as estomias, curativos, limpeza do colchão, troca dos lençóis, aspiração e administração de medicamentos, quando necessários, geralmente pela mesma pessoa que deu o banho. Alguns desses procedimentos pareciam ser desconfortáveis e dolorosos, como a aspiração. Entretanto, o mesmo procedimento, utilizando a mesma técnica, era realizado de formas diferentes tanto por profissionais quanto por acompanhantes. Alguns utilizavam recursos, verbais e corporais, durante esses cuidados, o que parecia deixar as crianças e os adolescentes mais confortáveis.

Outros profissionais, como médicos, fisioterapeutas, terapeutas ocupacionais, fonoaudiólogos e nutricionistas, começavam depois a circular pela enfermaria, então o barulho aumentava - os barulhos eram feitos pelos adultos, em sua grande maioria; o som das crianças que ecoava, por vezes, era o choro. Os atendimentos dos profissionais de saúde preenchiam grande parte do período da manhã. Algumas intervençôes modificavam a posição da criança no espaço, principalmente daquelas com comprometimento 
motor grave, e, consequentemente, alteravam suas possibilidades de interação com o meio.

O horário do almoço era marcado pelo esvaziamento de profissionais de saúde da enfermaria, pelo pouco movimento e o silêncio. Geralmente, ficavam apenas os enfermeiros e os técnicos de enfermagem no posto de enfermagem. Quanto à alimentação, não existia outro espaço para as crianças e os adolescentes comerem na enfermaria senáo os leitos. Para os que se alimentavam por via oral, a alimentação era realizada com a mediação de algum adulto, acompanhante ou técnico de enfermagem. A falta de espaço físico ou até mesmo de materiais para esse fim interferia na atividade. Entretanto, a grande maioria utilizava alguma tecnologia para alimentar-se: sonda, gastrostomia ou nutrição parenteral. Para a maioria dos sujeitos observados, a alimentação era uma atividade diária de responsabilidade e mediação da equipe de enfermagem, sem envolvimento direto, na grande maioria das vezes, da criança ou do adolescente no processo.

O final da tarde era marcado pelo esvaziamento dos profissionais de saúde da enfermaria, ficando apenas a equipe de enfermagem no posto. Era o momento em que as mães estavam mais próximas de seus filhos: as crianças e os adolescentes brincavam com seus pais ou dormiam. Como as intervençóes da equipe de saúde diminuíam, esse encontro podia acontecer quase sem interrupções. Muitas vezes, ele acontecia fora do leito, na poltrona do acompanhante, o que propiciava um maior contato corporal e também distanciava, da maneira possível, as duplas do local marcado pelas intervençóes - os leitos.

A noite não era só horário de descansar, pois a rotina de cuidados em saúde não parava. Uma mãe relatou em conversa informal que acordava a cada 3 horas para realizar cuidados com seu filho. Nas crianças e adolescentes que não estavam acompanhados, esses cuidados eram realizados pela equipe de enfermagem. Salvo algumas intercorrências, a rotina de cuidados em saúde se repetia todos os dias.

Talvez a particularidade mais evidente na vida cotidiana hospitalar seja que as atividades mais importantes, significativas e que demandam maior tempo são os cuidados relacionados ao corpo e à doença. De acordo com Heller (2008), a vida cotidiana é heterogênea sobre vários aspectos, principalmente no que se refere ao conteúdo e à significação das atividades. Assim, na vida cotidiana hospitalar, as atividades ligadas intimamente à sobrevivência dos que estáo hospitalizados se tornam, hierarquicamente, a esfera mais importante do cotidiano.

Podem-se relacionar essas particularidades na realização das atividades cotidianas com o conceito de espontaneidade e de mimese de Heller (2008), ou seja, a reprodução de uma atividade cotidiana com a forma particular que cada indivíduo coloca nela. Talvez nos procedimentos dolorosos, a liberdade na mimese seja mais facilmente identificada, pois mobilize os membros da equipe de saúde e o acompanhante a realizar a atividade de uma forma diferente para diminuir o desconforto da criança e do adolescente, e até o seu próprio incômodo.

Encontra-se que a vida cotidiana hospitalar é marcada por um ritmo fixo, pela repetição e pela regularidade. A rotina de cuidados configurou-se como um ciclo, uma engrenagem que não para, com sutis mudanças. Porém, apesar de os cuidados ligados ao corpo e à doença objetivarem a recuperação e a qualidade de vida das crianças e adolescentes hospitalizados, eles tinham poucos momentos de escolha durante o cuidado, exercendo pouca autonomia no cotidiano hospitalar. Tal repetição, aliada ao escasso espaço de liberdade na rotina e ao limitado exercício da autonomia, leva a pensar que isso pode ser um fator de risco para a alienação do cotidiano tanto da criança, adolescente e acompanhante hospitalizados como para a equipe de saúde (HELLER, 2008).

Heller (2008) menciona que o amadurecimento do homem ocorre pela aquisição de habilidades imprescindíveis para a vida cotidiana da sociedade em questão. Isso se dá por meio da assimilação da manipulação das coisas imprescindíveis para a cotidianidade em questão e das formas do intercâmbio ou comunicação social. Tais assimilaçóes são mediadas pelos grupos que estáo mais perto do sujeito (família, escola, comunidade), apresentando-lhe os elementos da cotidianidade, como os costumes, as normas e a ética. Nesse caso, o hospital acaba, muitas vezes, por tornar-se um território tão familiar que seus costumes, normas e ética são assimilados e reproduzidos pela criança, adolescente e acompanhante.

A exploração intensa dos objetos particulares do hospital e a imitação dos gestos dos profissionais de saúde pelas crianças e adolescentes hospitalizados pareceram ser uma tentativa de assimilação da vida cotidiana hospitalar. Como afirma Heller (2008), não há vida cotidiana sem a mimese, assim o grande desafio é produzir um campo de liberdade individual de movimentos no interior do processo de imitação. De certa forma, os acompanhantes e a equipe de saúde, quando atuam no papel de mediadores, incentivam e criam esses espaços de particularidades.

Para Heller (2008), o desenvolvimento do indivíduo é, antes de tudo, função de suas possibilidades de liberdade, que, nesse caso, podem ser favorecidas 
pela mediação. Ela é elemento essencial para que a criança e o adolescente vivam por inteiro a vida cotidiana hospitalar, sendo proporcionada tanto pelo acompanhante quanto pela equipe de saúde, pois se tornará um novo grupo social para esses sujeitos.

As flexibilizaçôes das rotinas de cuidado só costumavam acontecer quando havia a presença de um acompanhante. Aí se invertiam algumas rotinas, por exemplo, tomar banho de tarde. Esse período vespertino, em geral, era quando os acompanhantes estavam mais perto das crianças e dos adolescentes e podiam ter momentos juntos sem a interrupção dos profissionais de saúde. Também era marcado por maior tranquilidade e pela entrada de algumas atividades vinculadas a um projeto de leitura e a um programa institucional que leva o brincar para as enfermarias pediátricas. Observou-se que a participação efetiva das crianças e dos adolescentes nas atividades desenvolvidas por esses dois programas era incentivada ao ouvirem e valorizarem desejos expressados, mesmo que sutilmente. Nesses momentos, eles exerciam seu direito de escolher o que queriam fazer. À tarde também ocorriam a maior parte das visitas e a lavagem dos boxes, além de conversas da equipe de saúde com os familiares. O espaço disponível para as visitas era o espaço do box, o que restringia a interaçáo entre visitante, paciente e acompanhante.

Encontrou-se a mediaçáo do acompanhante se destacando mais nas crianças e nos adolescentes com grave comprometimento motor e cognitivo. Em geral, esses acompanhantes sentem uma maior necessidade de apresentar os estímulos externos de forma diferenciada, por meio do toque, cheiro, som etc., e conseguem perceber as sutilezas das respostas. Acabam por fazer o papel de porta-voz dessas crianças e jovens, ao identificar seus desejos e vontades e apresentá-los para o universo da hospitalização.

Como a enfermaria estudada tinha como público-alvo crianças e adolescentes com condiçốes crônicas de saúde, tal apropriação ficou evidente. $\mathrm{Na}$ impossibilidade de estar em casa, a dupla acompanhante-criança/adolescente transformava o espaço hospitalar em algo mais pessoal e personalizado, utilizando os espaços de liberdade possíveis e particularizando esse ambiente com objetos pertencentes ao universo domiciliar. Acredita-se que isso influencie no aumento da potência de açáo tanto das crianças e dos adolescentes hospitalizados como dos acompanhantes.

Mas, na vida cotidiana hospitalar, os espaços de particularidades estão em constante jogo com a alienação. Isso porque a vida cotidiana, segundo Heller (2008), presta-se à alienação. A assimilação das normas consuetudinárias dominantes do hospital pode converter-se em um conformismo, e a criança e o adolescente hospitalizados, bem como seus acompanhantes, podem ser engolidos por seus papéis e agir com o que se "espera" deles. Existe uma divisão tênue e tensa entre a alienação da vida cotidiana hospitalar e a sua real apropriação, justificada talvez pela estrutura hospitalar que é, muitas vezes, inflexível e generalizadora. Ora são criados espaços de liberdade e margem de movimento na estrutura da vida cotidiana hospitalar, ora essa estrutura se cristaliza, muitas vezes, por conflitos decorrentes dessa apropriação.

Ao buscar a apropriação da vida cotidiana hospitalar, é necessário permitir a margem de movimento na sua estrutura e comportamento, levando-se em conta as singularidades dos sujeitos. Galheigo (2003) afirma que, ao trabalhar com o processo de singularização, precisa-se recusar a submissão de um papel social tal como pede a relação de alienação e opressão social, e reapropriar-se, de forma criativa, dos componentes da subjetividade. Quando se faz isso, coloca-se o sujeito no centro da atenção, bem como os significados que ele dá às suas experiências, ou seja, o foco passa a ser sua compreensão e interpretação da realidade social.

Heller (2008) coloca que, quando existe uma grande lacuna entre o humano-genérico e as possibilidades de desenvolvimento dos indivíduos humanos, entre a produçáo humano-genérica e a participação consciente do indivíduo nessa produçãa, há a alienação do cotidiano. Para a autora,

[...] as formas necessárias da estrutura e do pensamento da vida cotidiana náo devem se cristalizar em absolutos, mas têm de deixar ao indivíduo uma margem de movimento e possibilidades de explicitação (HELLER, 2008, p. 56).

Nesse sentido, a alienação da vida cotidiana hospitalar, principalmente nos casos de hospitalizaçóes prolongadas, pode ser um fator que diminui a potência de agir tanto de crianças e de adolescentes hospitalizados quanto de seus acompanhantes.

\subsection{Hospital como território: espaço, objetos e cadeias operatórias}

Como o hospital carrega muitas particularidades, como o espaço hospitalar com os seus objetos característicos - leitos, fios, aparelhos de suporte ventilatório, bombas de infusão, gaze, esparadrapo, seringas, entre tantos outros -, esses fazem parte das cadeias operatórias de crianças e de adolescentes no processo de hospitalização. As cadeias operatórias constituem os modos de vida de cada indivíduo, sendo uma cadeia de gestos que, apesar de estar no domínio do banal do cotidiano, caracteriza e 
dá fluidez a cada sujeito. Leroi-Gourhan (2002) intitula as cadeias operatórias como as repetiçóes dos gestos que asseguram o equilíbrio do sujeito e seu conforto psíquico no meio social, sendo o jeito particular como cada pessoa realiza determinada atividade, envolvendo não apenas os movimentos em si, mas também ritmo e sequenciamento ou ordem. De acordo com Marquetti e Kinoshita (2011), a vida é composta por gestos ínfimos e elementares que, embora pareçam insignificantes, possibilitam o viver no cotidiano.

Ao olhar para a vida cotidiana hospitalar, encontra-se que as cadeias operatórias realizadas no hospital por crianças e adolescentes acontecem, na sua quase totalidade, no leito e são compartilhadas tanto com a equipe de saúde quanto com outras crianças e adolescentes que estão hospitalizados e seus acompanhantes. Tal fato é influenciado pela condição clínica, que requer o suporte de aparelhos tecnológicos, e pelo espaço, que é organizado para favorecer o monitoramento da equipe de saúde.

Móveis destinados às crianças, adolescentes e acompanhantes (leitos, poltronas e armários) estavam organizados a fim de favorecer a visualizaçáo e o monitoramento para os profissionais de saúde: os leitos ficavam dispostos com a cabeceira virada para o posto de enfermagem; a poltrona do acompanhante ficava aos pés do leito; $\mathrm{e}$ as portas dos boxes estavam geralmente abertas. A privacidade, a interação entre as crianças e os adolescentes e o conforto estavam em segundo plano.

Essa disposição, ao mesmo tempo que não prezava pela privacidade, permitia que o cotidiano da enfermaria como um todo fosse compartilhado, seja pela parede de acrílico, portas abertas ou disposição dos boxes. Esse compartilhamento ia desde situaçóes banais, como atividades de higiene e interaçóes entre crianças de diferentes boxes, até momentos delicados, como conversas de familiares com a equipe, discussóes de casos e realização de procedimentos.

A falta de privacidade, principalmente nas atividades de higiene, era uma grande ruptura que a hospitalização provocava. Tais atividades, quando realizadas em casa, provavelmente eram feitas no banheiro ou no quarto, e, mesmo que compartilhadas com outra pessoa, possivelmente seria com alguém com quem a criança ou o adolescente tivesse um laço afetivo ou familiar. Na hospitalização, na grande maioria das vezes, essas atividades de higiene eram compartilhadas com profissionais de saúde e outras famílias que ali estavam. Para crianças pequenas e seus acompanhantes, a exposição das atividades de higiene parecia não causar tanto impacto ou constrangimento. Entretanto, para adolescentes, alguns indícios de que essa exposição causava constrangimento foram percebidos, como o pedido verbal de uma adolescente para usar o banheiro e não a comadre, mesmo que isso mobilizasse a equipe a fazer vários arranjos com a bomba de infusão e a cadeira de rodas.

Outra cena comum era ver crianças, principalmente, olhando através da divisória de acrílico os acontecimentos da enfermaria. Esse olhar curioso acompanhava a movimentaçáo de profissionais, os procedimentos, as brincadeiras, a criança que estava no box ao lado, a vida daquela enfermaria. Muitas vezes, esse olhar parecia pedir explicações acerca do que estava acontecendo com a outra criança; outras vezes, parecia chamar e convidar a criança ou o profissional para brincar ou conversar; em outros momentos, demonstrava medo, susto, surpresa. Por vezes, o acompanhante mudava a disposição do mobiliário do box, colocando, geralmente, a poltrona de costas para o posto de enfermagem, como durante a presença de uma visita, um momento de descanso ou de lazer. Essa mudança parecia indicar um pedido de privacidade de forma delicada, sutil.

Pode-se caracterizar a hospitalizaçáo como uma ruptura no cotidiano, que confronta o sujeito a modificar suas cadeias operatórias para alcançar o equilíbrio psíquico e o conforto nesse novo modo de viver - a vida cotidiana hospitalar. Essas rupturas exigem que crianças e adolescentes desencadeiem o comportamento lúcido, que leva à constituição de novas cadeias operatórias. No caso da hospitalização prolongada, as novas cadeias operatórias (principalmente das atividades de higiene, alimentação e locomoção) serão incorporadas ao comportamento maquinal ${ }^{3}$. Esse processo é de extrema importância por estar ligado diretamente à apropriação da vida cotidiana hospitalar, além de ser impossível pensar em um comportamento operatório que exija uma constante lucidez (LEROI-GOURHAN, 2002).

Como afirma Barros (2011), as rupturas são fatos que acontecem incessantemente na vida, porém, dependendo de seu impacto, os indivíduos irão conseguir ou não reestruturar suas cadeias operatórias e alcançar o equilíbrio na vida cotidiana. Nessa reestruturação das cadeias operatórias, encontra-se um papel fundamental desempenhado pela equipe de saúde e pelo acompanhante, seja no apoio realizado na atividade em si ou na operacionalização de algumas estratégias para que a atividade aconteça da melhor maneira para o sujeito.

No entanto, acredita-se que, em longo prazo, a não reestruturação das cadeias operatórias pode ser um fator de diminuição de potência de ação 
de crianças e de adolescentes hospitalizados. Como afirmam Marquetti e Kinoshita (2011), o caráter constitutivo das atividades elementares só é notado quando há rupturas nas cadeias operatórias e se perde a possibilidade de agir na forma inscrita da memória de corpo, de gestos, de sensibilidade e sentidos. Para os autores, quando não há a criação de novas cadeias operatórias:

[...] o sujeito perde o sentido do seu cotidiano e assim se desenraiza da sua vida habitual. A perda de pequenos gestos, açóes e atividades podem desorganizar o sentido de vida dado pelo cotidiano, pois o sujeito ao agir no cotidiano através de suas cadeias operatórias, concomitantemente, estrutura a si mesmo e a sua vida (MARQUETTI; KINOSHITA, 2011, p. 220).

Outro ponto marcante foi ver como os objetos hospitalares permeavam as relaçóes e as cadeias operatórias (da alimentaçáo, do lazer, do descanso etc.) do cotidiano de crianças e de adolescentes hospitalizados. Os objetos hospitalares estavam presentes na quase totalidade das atividades e encontros que se deram nesse espaço. Isso ocorria tanto na realização dos procedimentos, que envolvia a utilização de luvas, capotes e máscaras, por parte dos profissionais, quanto na exploração desses objetos pelos pacientes.

As crianças pequenas, principalmente, que não tinham grande comprometimento motor, exploravam esses objetos de maneira intensa. Apropriavam-se de objetos e rotinas, solicitando sua utilização nas atividades mais corriqueiras. Era comum vê-las mexendo nos fios dos acessos, estomias, bombas de infusão, pacotes de gaze e outros. Alguns desses objetos funcionavam como a extensão de seus corpos, condiçấo vital para a sobrevivência, e eram incorporados nas cadeias operatórias.

Essa exploração ativa, corporal, é característica da faixa etária em que essas crianças se encontravam. Assim, usavam os mesmos mecanismos que utilizariam fora do hospital para explorar o próprio corpo e o ambiente à sua volta. Porém, por estarem no hospital, entravam em contato com os objetos particulares desse ambiente e que, provavelmente, nem conheceriam se não estivessem internadas. O contato constante com tais objetos levava-os a ser incorporados no repertório das cadeias operatórias, tornando-se objetos comuns, conhecidos e de seu domínio.

Com isso, as crianças e os adolescentes hospitalizados nessa enfermaria, principalmente pela dependência tecnológica, construíram cadeias operatórias diferentes daquelas que culturalmente são comuns. Um exemplo era a alimentação, uma cadeia operatória automática, ligada à natureza biológica. Como a quase totalidade não se alimentava pela boca, a qual é a via comum para a alimentação, as cadeias operatórias alimentares desses sujeitos eram permeadas por objetos hospitalares que, ao mesmo tempo que mudavam o "curso biológico da alimentação", garantiam sua sobrevivência.

Os objetos hospitalares também substituíam o brinquedo ou faziam o papel de objeto transicional. Objetos utilizados durante os cuidados de higiene e nos cuidados em saúde eram frequentemente oferecidos para as crianças, e elas os exploravam, muitas vezes tornando a ação em uma brincadeira. Outras vezes, profissionais enchiam luvas de procedimento e ofereciam para a criança como um brinquedo ou para acalmá-la.

No entanto, apesar de todos os equipamentos tecnológicos e objetos desse ambiente, muitos profissionais e voluntários conseguiam estabelecer com as crianças e os adolescentes encontros nos quais esses elementos eram incorporados nas relaçóes. O que se destacava era o desejo e o prazer desse encontro. Tais encontros remetiam a uma naturalidade que aquela cena parecia estar acontecendo fora daquele ambiente controlado e focado na recuperação e manutençáo da saúde. Isso era potencializado pela incorporação dos objetos hospitalares nas cadeias operatórias de ambos os atores e pela sua generalização para além das atividades específicas, transbordando para as atividades de lazer, descanso e para o brincar.

Em relação à utilização dos objetos hospitalares, na quase totalidade das cadeias operatórias, pode-se inferir que muitos deles, que estão ligados à sobrevivência e aos cuidados diários de saúde, são inseridos desde muito cedo na vida de crianças e de adolescentes com condiçôes crônicas e complexas de saúde, como é o caso das estomias, gazes, luvas, sondas, ambus, aspiradores, entre outros. Com o tempo, a partir da sua utilização, exploração e apropriação, essas crianças e adolescentes extrapolavam esses objetos para as cadeias operatórias do brincar, lazer, descanso, alimentaçáo etc.

Olhando para aquelas crianças que, por disfunçóes orgânicas, estavam passando a maior parte da infância no hospital, percebe-se que alguns de seus sistemas foram modificados desde o nascimento ou muito cedo, tendo aparelhos e tecnologias incorporados em seu corpo para substituir determinadas funçóes orgânicas. Assim, algumas cadeias operatórias automáticas não chegaram nem a ser experimentadas, como a alimentação, por exemplo, no caso de crianças com gastrostomia ou nutrição parenteral. 
É importante destacar que o curso biológico das atividades ligadas às cadeias automáticas, de muitas das crianças e dos adolescentes internados, tinha sofrido modificaçôes significativas devido aos cuidados necessários aos processos de tratamento. Com isso, tais cadeias operatórias ficavam condicionadas ao funcionamento de aparelhos (como bilevel, bomba de infusão e outros) ou ao uso de tecnologias em saúde, como estomias, derivaçôes, órteses, dentre outros.

Essa situação deve ser foco de cuidado dos profissionais de saúde, pois, segundo Marquetti e Kinoshita (2011), a maior parte das cadeias operatórias é construída na infância e adolescência, sendo fundamentais para a constituição do sujeito. Esses autores apontam que o sujeito emerge quando incorpora um conjunto de cadeias operatórias socialmente consensuadas e que viabilizam o seu conviver. Ao olhar para essas crianças e adolescentes, é inevitável pensar em seu desenvolvimento enquanto sujeitos, mesmo com a privação ou alteração de algumas sensaçôes, e também ver como cadeias operatórias automáticas e maquinais podem ser viabilizadas por meio das tecnologias em saúde, criando novas formas consensuadas de viver.

Percebe-se também que a presença do acompanhante influenciava a presença de adaptaçóes e objetos não hospitalares e pessoais no cotidiano de crianças e de adolescentes hospitalizados. Por meio da presença de brinquedos, DVDs, banheiras de plástico, lençóis coloridos, fotos e outros objetos, levavam singularidade ao ambiente hospitalar. Em geral, a presença desses objetos nos leitos estava ligada ao tempo de internação e ao comprometimento motor e cognitivo da criança e do adolescente. Sua presença indicava uma apropriação desse espaço e das rotinas hospitalares e sua utilização, bem como sua disposiçáo no leito estava relacionada com a presença, ou não, do acompanhante.

Geralmente, quando o acompanhante estava presente, os objetos pessoais (principalmente os brinquedos) ficavam no leito, e a criança e o adolescente tinham livre acesso a eles. Porém, sobretudo quando estavam desacompanhados, esses objetos ficavam na poltrona, armário e batente da janela, dificultando o acesso da criança e necessitando de um mediador para pegá-los. Já os adolescentes, mesmo desacompanhados, pegavam eles mesmos ou pediam para alguém.

Nem sempre a equipe percebe o valor da utilização desses objetos para a criança ou para a própria mãe. Os objetos não hospitalares utilizados nas rotinas diárias ou dispostos no leito passavam a sensação de "estar em casa", de apropriação do espaço hospitalar, e tornavam o cuidado singular, assim como singulares também são as crianças e os adolescentes, nesse ambiente, muitas vezes, generalizador.
É importante destacar que as diversas açóes que acontecem no cotidiano hospitalar podem modificar a potência de ação de crianças e de adolescentes hospitalizados, bem como de seus acompanhantes. Isso vai ao encontro das ideias de Spinoza (2013), de que a potência de ação é modificada pelas afetações no corpo que o sujeito sofre nas relaçóes com os outros sujeitos e também com o meio à sua volta.

Nessa perspectiva, na vida cotidiana hospitalar existem interaçóes, situaçóes e relaçóes que a criança, o adolescente e o acompanhante vivenciam que podem aumentar sua potência de ação, ou seja, aumentar sua força e sua intensidade enquanto indivíduo. No entanto, também existem vivências que podem diminuir a potência de ação, diminuir sua força, sua intensidade, causar tristeza, apatia.

É importante ainda lembrar que, de acordo com o conceito de Spinoza (2013), a afetação é singular, tanto em relação ao indivíduo quanto ao momento que ele está vivendo. Uma situação pode desencadear o aumento de potência em uma criança e, em outra, ser fator de diminuição ou mesmo não interferir em sua potência. Isso depende do indivíduo e do momento que ele está vivendo.

Assim, durante as observaçôes, pôde-se perceber que algumas situaçóes da vida cotidiana hospitalar, como a privação do convívio familiar, diminuíam a potência de ação de algumas crianças e adolescentes. Já para outros, tal fato parecia não afetar a potência de ação. Porém, determinadas situaçóes pareceram centrais durante as observaçóes, com a possibilidade de serem generalizadas como açóes que influenciam no aumento e na diminuiçáo da potência de ação de crianças e de adolescentes hospitalizados.

Destaca-se como principal fator de diminuição de potência de ação durante a hospitalização a falta de autonomia que as crianças e os adolescentes têm no processo de cuidado, seja nas atividades mais básicas, como banho e alimentação, ou nas decisões e diálogo com a equipe de saúde sobre os procedimentos e os cuidados necessários. Encontrou-se, de forma recorrente durante a observaçáo, a passividade nas atividades cotidianas. Isso ocorria principalmente nas crianças pequenas, sem domínio da linguagem verbal e desacompanhadas. Para estas, o silêncio permeava a maioria dos atendimentos (nos momentos em que o diálogo era necessário, os membros da equipe de saúde dirigiam-se, prioritariamente, aos acompanhantes). Tais condutas colocavam a criança e o adolescente como espectadores no processo de seu próprio cuidado em saúde e diminuíam sua intensidade enquanto indivíduo.

Em contrapartida, observou-se também o contraste na postura da criança e do adolescente quando a 
intervenção valorizava a autonomia, o desejo e a participação. Isso ficava evidente pelo sorriso, mudança corporal, maior verbalização e diminuição de expressóes desagradáveis, entre outras posturas. Em tais situaçóes, parecia haver um alargamento da criança e do adolescente em questão, possibilitando estabelecer relaçôes mais intensas com o meio e as pessoas à sua volta.

Outro fator importante no aumento ou na diminuição da potência de ação é a apropriação, ou não, da vida cotidiana hospitalar. Quando a dupla criança/adolescente-acompanhante apropria-se desse cotidiano, cria-se um terreno mais fértil para as açóes de aumento de potência: as cadeias operatórias são modificadas e incorporadas, possibilitando, assim, que a vida seja vivida por inteiro durante a hospitalização. Porém, quando esse cotidiano se torna alienado, as cadeias operatórias não são restituídas. Isso faz com que o cotidiano perca sentido, e as crianças e os adolescentes hospitalizados se desenraízem de sua vida habitual (MARQUETTI; KINOSHITA, 2011).

Acredita-se que uma estratégia possível para o aumento da potência de ação de crianças e de adolescentes hospitalizados seja a restituição das cadeias operatórias, na medida em que elas são um veículo para alcançar a apropriação da vida cotidiana hospitalar e, assim, poderiam permitir que se viva por inteiro na cotidianidade. Como afirmam Marquetti e Kinoshita (2011), é comum acreditar que o sentido da vida é construído por meio de eventos importantes, atos que estáo fora da rotina, celebraçóes incomuns, atos únicos, entre outros. Porém, esses eventos são as suspensôes do cotidiano e não significam nada se não estiverem no conjunto de açóes e de emoçóes coordenado ao presente. Para esses autores, "[...] a vida acontece, diariamente, no cotidiano" (MARQUETTI; KINOSHITA, 2011, p. 219). Nesse sentido, para as crianças e os adolescentes internados, a vida cotidiana é a rotina hospitalar, composta pelas açôes e atividades desse espaço, aí incluindo procedimentos, cuidados em saúde, objetos hospitalares e a equipe de saúde. Apesar de a hospitalização gerar uma ruptura no cotidiano de crianças e de adolescentes internados, eles criam um cotidiano particular durante esse período, a vida cotidiana hospitalar.

\section{Conclusão: Relações, Fios Tecidos, Encontros}

O estudo do cotidiano de uma enfermaria pediátrica de média e alta complexidade mostrou que este é permeado por intervençôes da equipe de saúde e que crianças e adolescentes têm pouco espaço para exercer a autonomia nos cuidados em saúde. Percebeu-se também que os espaços para outras atividades, além das relacionadas ao cuidado, são escassos, e os objetos hospitalares estão presentes na quase totalidade das cadeias operatórias, extrapolando aquelas ligadas aos cuidados em saúde. Pelo fato de a enfermaria estudada ter como característica a internação de crianças e de adolescentes com condiçóes crônicas e complexas de saúde, com internaçóes prolongadas e recorrentes, o risco de o cotidiano tornar-se alienado é alto. A falta de autonomia nos cuidados em saúde e a alienação da vida cotidiana hospitalar, muitas vezes, diminuem a potência de ação de crianças e de adolescentes hospitalizados, e até mesmo de seus acompanhantes.

Por todas as mudanças que a hospitalização acarreta, pode-se caracterizá-la como um evento que leva a uma ruptura do cotidiano e que pode gerar um desequilíbrio nas cadeias operatórias das diversas atividades realizadas no dia a dia. Tal ruptura confronta os sujeitos a modificar suas cadeias operatórias para alcançar o equilíbrio psíquico e o conforto nesse novo modo de viver - a vida cotidiana hospitalar.

Porém, dependendo do seu impacto, os indivíduos conseguirão ou não reestruturar suas cadeias operatórias e alcançar o equilíbrio na vida cotidiana. Nesse processo de reestruturação, a equipe de saúde e o acompanhante são peças fundamentais, seja no apoio realizado na atividade em si ou na operacionalização de algumas estratégias para que a atividade aconteça da melhor maneira para a criança e para o adolescente. São eles que apresentam o universo hospitalar e suas rotinas. Quando crianças e adolescentes se apropriam desse cotidiano, assimilando tanto os objetos como as regras sociais particulares desse ambiente e incorporam um conjunto de cadeias operatórias socialmente consensuadas e que viabilizam o seu conviver, conseguem viver a cotidianidade na hospitalização. Nesse processo, a presença do acompanhante, principalmente para crianças e adolescentes com grave comprometimento motor e cognitivo, é fundamental.

Outro ponto de destaque para a problematizaçáo das intervençóes da equipe de saúde são as crianças e os adolescentes que, por condiçóes crônicas de saúde, têm algumas cadeias operatórias condicionadas ao funcionamento de aparelhos ou ao uso de tecnologias em saúde. O desenvolvimento desses sujeitos se dá mesmo com a privação de algumas experiências sensoriais, e a dependência dos aparelhos e das tecnologias em saúde cria novas formas consensuadas de viver, diferentes da maioria das crianças e dos adolescentes, mas legítimas para eles. Tais fatos devem ser problematizados tanto nas intervençóes 
e nos projetos terapêuticos singulares dentro do hospital quanto fora dele.

Este estudo não teve a pretensão de esgotar o tema do cotidiano de crianças e de adolescentes hospitalizados em enfermarias pediátricas de média e alta complexidade, mas refletir e dar destaque a essa temática à luz dos referencias teóricos utilizados. Novos estudos são necessários, principalmente, para aprofundar a questão do cotidiano das crianças que passam a maior parte da sua infância, ou mesmo sua vida toda, ainda que curta, no hospital.

Enfim, acredita-se que também seja papel da equipe de saúde problematizar a vida cotidiana hospitalar e, por meio de tecnologias relacionais, criar, facilitar e valorizar os espaços de liberdade possíveis e o exercício da autonomia. Trata-se de uma estratégia para aumentar a potência de ação das crianças e dos adolescentes hospitalizados e seus acompanhantes. Tais ações caminhariam para que esses sujeitos pudessem conduzir sua vida cotidiana hospitalar com maior autonomia, ou seja, incorporar o conjunto de cadeias operatórias socialmente consensuadas e que viabilizam o seu conviver, apropriar-se a seu modo da realidade e impor a ela a marca da sua personalidade, tendo, com isso, maior qualidade de vida e valores singulares.

\section{Referências}

BARROS, A. C. S. Conceituação e prática da matriz teórica do módulo de ensino "A açáa como precursora do pensamento humano": inventário de potência - campo A. 2011. Monografia (Graduação em Terapia Ocupacional) - Universidade Federal de São Paulo, Santos, 2011.

FEUDTNER, C.; CHRISTAKIS, D. A.; CONNELL, F. A. Pediatric deaths attributable to complex chronic conditions: a population-based study of Washington State, 1980-1997. Pediatrics, United States, v. 106, p. 205-209, 2000. Suplemento 1.

GALHEIGO, S. M. O cotidiano na terapia ocupacional: cultura, subjetividade e contexto histórico-social. Revista de Terapia Ocupacional da USP, São Paulo, v. 14, n. 3, p. 104-109, 2003.

HELLER, A. O cotidiano e a história. São Paulo: Paz e Terra, 2008.

LAPLANTINE, F. Aprender antropologia. São Paulo: Brasiliense, 2000.

LEFEBVRE, H. A vida cotidiana no mundo moderno. São Paulo: Ática, 1991.

LEROI-GOURHAN, A. O gesto e a palavra 2: memória e ritmos. Portugal: Ediçōes 70, 2002.

MARQUETTI, F. C.; KINOSHITA, R. T. A ação como precursora do pensamento no humano. Cadernos de Terapia Ocupacional da UFSCar, São Carlos, v. 19, n. 2, p. 215-228, 2011.

MINAYO, M. C. S. O desafio do conhecimento: pesquisa qualitativa em saúde. São Paulo: Hucitec, 2010.

MITRE, R. M. A.; GOMES, R. A promoção do brincar no contexto da hospitalizaçáo infantil como açáo de saúde. Ciência \& Saúde Coletiva, Rio de Janeiro, v. 9, n. 1, p. 147-154, 2004.

SANTA ROZA, E. Um desafio às regras do jogo. In: SANTA ROZA, E. Da análise na infância ao infantil na análise. Rio de Janeiro: Contracapa, 1997. p.161188.

SPINOZA, B. Ética. Belo Horizonte: Autêntica, 2013.

VELHO, G. Observando o familiar. In: NUNES, E. (Ed.). A aventura sociológica. Rio de Janeiro: Zahar, 1978. p. 123-132.

\section{Contribuição dos Autores}

Mariana Pereira Simonato responsabilizou-se pela concepção da pesquisa, revisão do artigo, coleta e análise de dados e redação dos resultados. Rosa Maria de Araujo Mitre responsabilizou-se pela orientação, concepção da pesquisa e revisão do artigo. Todos os autores aprovaram a versão final do texto.

\section{Notas}

${ }^{1}$ Esta pesquisa foi autorizada pelo Comitê de Ética, Plataforma Brasil, CAAE no 27978614.0.0000.5269, e está de acordo com a resolução do Conselho Nacional de Saúde no 466/12. Este artigo se baseia na pesquisa que deu origem a monografia de título homônimo para obtenção do título de especialista em uma instituição de ensino, pesquisa e assistência da região Sudeste do país.

${ }^{2}$ Definida por Feudtner, Christakis e Connell (2000) como qualquer condição médica que possa ser razoavelmente esperada para durar pelo menos 12 meses (a não ser que ocorra a morte) e envolva vários sistemas diferentes ou um sistema severamente, o suficiente para exigir cuidados especiais pediátricos e provavelmente algum período de internação em um centro de atendimento terciário.

${ }^{3}$ Constituem a base do comportamento individual comum aos membros de um mesmo grupo étnico e situam-se em uma zona profunda da memória coletiva, mantendo uma relação limitada com a linguagem. São alguns exemplos, os gestos que encadeamos durante a higiene corporal, as refeiçôes, a escrita, o caminhar e o transporte (LEROI-GOURHAN, 2002). 